\title{
Limb Deformity Correction Using the Ortho SUV Frame
}

\author{
Juanito S. Javier, MD, MChOrth, ${ }^{1}$ Ruel A. dela Cruz, $M D^{1}$ and Daniel V. Dungca, $M D^{2}$ \\ ${ }^{1}$ Department of Orthopedics, Philippine General Hospital, University of the Philippines Manila \\ ${ }^{2}$ Dr. Jose R. Reyes Memorial Medical Center
}

\begin{abstract}
Background and Objective. Limb deformity in terms of length discrepancy, angular and rotational deformities are amenable to correction using the llizarov method. The corrections can be achieved using the Ortho SUV Frame (OSF), a computer assisted six axes external fixator. Previous studies have reported easier and more accurate deformity correction. In this study, we report on our initial experience and treatment outcomes in using this system.

Materials and Methods. This study is a case series of patients where the llizarov circular frame was applied and which the deformity correction was carried out using the OSF. Success and accuracy in correction, length of time to correct, number of revisions needed and complications were gathered from a review of medical records.

Results. Thirty limbs in twenty nine cases were included in this report. Seventy seven percent $(23 / 30)$ of the deformities were due to previous trauma. The rest were due to Blounts, infection and tumor. Correction in eighty seven percent $(26 / 30)$ were achieved using the turning schedule provided by the Ortho SUV application software. Three cases required surgical removal of soft tissue interposition before further correction using the software was achieved. One case with posterior translation underwent closed manipulation. In the end all planned deformity corrections were achieved. Complications included pin tract swelling and erythema in $13 \%$ and all resolved either with oral antibiotics alone or combined with surgical release of pin sites under local anesthesia.
\end{abstract}

Conclusion. The Ortho SUV is an effective tool to carry out deformity corrections using the llizarov method.

Key Words: limb deformity, Ortho SUV, llizarov method, six axes external fixator

\section{INTRODUCTION}

Presented (Podium) in the $3^{\text {rd }}$ World Ortho ReCon - ILLRS \& ASAMI Congress, August 29 to September 2, 2017, in Estoril, Portugal.

Corresponding author: Juanito S. Javier, MD, MChOrth Department of Orthopedics Philippine General Hospital

University of the Philippines Manila

Taft Avenue, Manila 1000, Philippines

Email: jsjavier6@up.edu.ph
Limb deformities can be angular, rotational, translational, longitudinal, or a combination of all of these. Presence of these deformities alter the proper transmission of forces across adjacent joints, leading to alterations in the patient's function. ${ }^{1}$ This means alterations in gait if the deformity is in the lower extremity and in the long term could lead to early degenerative arthritis. Causes of the deformities are varied from congenital abnormalities, trauma, infection, metabolic abnormalities or tumor.

Correction of these limb deformities poses a great challenge even to the most experienced orthopedic surgeon. Each deformity can be managed differently depending on several factors such as surgeon's experience and preference, availability of implants, health institution facilities, deformity personality, and chronicity. ${ }^{1-3}$ The Ilizarov method using circular frame and conventional hinges have been utilized for deformity correction. ${ }^{4}$ In lieu of the traditional hinges, the Ortho SUV Frame (OSF), a computer assisted six axes external fixator has been used.5,6 


\section{THE ORTHO SUV FRAME}

The Ortho SUV Frame (OSF) and its software was introduced in 2006. Its name is derived from the first letter of the names of its 3 innovators, Leonid Solomin, Alexander Utekhin, and Viktor Vilensky. ${ }^{6}$ The frame is one of the many types of six axes external fixators or hexapods used for correcting deformities. This system operates based on a platform different from those used by other hexapods such as the Taylor Spatial Frame. ${ }^{7}$ It is different also in that the actual x-ray image is used for the calculation of turning schedules and that the struts can be attached to any kind or model of circular frame and at different levels. After achieving the corrected position, the OSF struts are then replaced with regular bridging threaded rods.

It is called hexapods because of the six connecting struts that obliquely crosses the site of deformity. A computer software program determines the position of the two bony components of the deformity. Changing the lengths of the struts moves the mobile bony part and by following the table of strut lengthening as generated by the computer software, the mobile bone is made to properly align with the other bony component.

\section{THE PROCESS OF CORRECTION USING THE ORTHO SUV FRAME ${ }^{7}$}

After the Ortho SUV Frame is attached, standard antero-posterior and lateral radiographs are taken. A radiopaque marker is placed on the film cassette marking where the center of beam lands (cross grid marker of the $\mathrm{x}$-ray machine is used to approximate this). The distance of the plate to the $x$-ray head is measured. The length of each of the six struts are measured. The 3 joints (where the struts meet) in the base ring form a triangle. The other 3 joints in the mobile ring form another triangle. The legs of these triangles are measured. All the parameters mentioned are inputted into the software program. The radiographic images are also uploaded into the program. Once these parameters are inputted, the user would be required to do the following steps; 1 . Locate the center of the $\mathrm{x}$-ray beam on the radiographic image; 2 . confirm the scale of the image; 3. identify the joints and trace the axis of the struts. The program user would then be required to trace the outlines of the base bone fragment and mobile fragment on the $\mathrm{x}$-ray images being used. The axes of the bone fragments are also drawn. Fragment markers will then be generated and these are manipulated to dictate the correction of the movement of the mobile fragment (angular and length corrections). The surgeon then identifies the structures at risk and dictates the rate and rhythm of distraction per day. Correction of rotation is also allowed. The software will then generate a turning schedule for each of the struts and will show the number of days for correction to be attained. For correction acutely of fractures, all one needs to do is just reset the 6 struts to the final length as shown in the table generated. The struts have threaded clutch mechanism which provides the strut the flexibility to become longer as needed. This is unlike in some hexapod systems where one may need a supply of extra struts with different lengths to cover the course of treatment. In the OSF, only the 6 original struts are all that are required to complete the correction.

The application of the Ortho SUV Frame and the use of the software program is meticulously described in readily available manuals from the originators and a short workshop is all that is required to learn how to use the OSF. ${ }^{7}$

Prior to this period, the 2 senior authors have relied on traditional Ilizarov hinges to correct major deformities. This paper presents the results of the first three years experience of the two authors on the use of the OSF in the Philippines.

\section{MATERIALS AND METHODS}

Medical records of patients with limb deformities treated using the Ortho SUV Frame (manufactured by S.H. Pitkar, Orthotools, Pvt.,Ltd.) by the 2 senior authors (JSJ and DVD) from October 2012 to September 2015 were reviewed. Excluded from the study were those patients who are still in the process of deformity correction during the time of review, incomplete records and patients who were not able to finish the deformity correction or were lost to follow up.

The following data were collected:

- Patient's demographics

- Cause of deformity

- Extremity involved

- Details of the correction using the Ortho SUV

- Outcome of correction

- Total number of days for correction - defined as number of days needed to obtain good alignment in all planes

- Number of revisions

- Complications

The total time in the fixator (from application to consolidation) was not included in the study. The list of patients is in no particular order, meaning the patients were treated with OSF, as the surgeon sees fit regardless of the complexity of the deformity.

Deformities were first classified as having one or more of the following components: axial translation (shortening or over-lengthening), peripheral translation, angulation, or rotation (torsion). The deformities were then categorized as simple, middle or complex depending on how many components were present based on the practical classification of long bone deformities by Solomin et al. ${ }^{6}$

Data were tabulated. The demographics of the patients were noted and results were described in terms of central tendencies and ratios. 
Table 1. Practical classification of Long Bone Deformities*

\begin{tabular}{|c|c|c|c|}
\hline & One-plane & Two-plane & Three-Plane \\
\hline One-component & $\begin{array}{l}\text { - Translation in one standard plane } \\
\text { - Angulation in one standard plane } \\
\text { - Axial translation } \\
\text { - Rotation }\end{array}$ & & \\
\hline Two-component & $\begin{array}{l}\text { - Axial translation + rotation } \\
\text { - Translation in one standard plane + } \\
\text { rotation } \\
\text { - Angulation in one standard plane + } \\
\text { rotation }\end{array}$ & $\begin{array}{l}\text { - Translation in two standard planes } \\
\text { - Angulation in two standard planes } \\
\text { - Translation in one stand standard } \\
\text { plane + angulation in one standard } \\
\text { plane } \\
\text { - Angulation in one standard plane + } \\
\text { axial translation } \\
\text { - Translation in one standard plane + } \\
\text { axial translation }\end{array}$ & \\
\hline Three-component & & $\begin{array}{l}\text { - Translation in two standard planes + } \\
\text { rotation } \\
\text { - Angulation in two standard planes + } \\
\text { rotation } \\
\text { - Translation in two standard planes + } \\
\text { angulation in one standard plane } \\
\text { - Angulation in two planes + } \\
\text { translation in one standard plane } \\
\text { - Translation in one standard plane + } \\
\text { angulation in one standard plane+ } \\
\text { rotation }\end{array}$ & $\begin{array}{l}\text { - Angulation in two standard planes + } \\
\text { axial translation } \\
\text { - Translation in two standard planes + } \\
\text { axial translation } \\
\text { - Translation in one standard plane + } \\
\text { angulation in one standard plane + } \\
\text { axial translation }\end{array}$ \\
\hline Four-component & & $\begin{array}{l}\text { - Translation in two planes + } \\
\text { angulation in one standard plane + } \\
\text { rotation } \\
\text { - Translation in two planes + } \\
\text { angulation in two planes } \\
\text { - Angulation in two planes + } \\
\text { translation in one standard plane + } \\
\text { rotation }\end{array}$ & $\begin{array}{l}\text { - Angulation in two standard planes + } \\
\text { axial translation + rotation } \\
\text { - Translation in two planes + } \\
\text { angulation in one standard plane + } \\
\text { axial translation } \\
\text { - Translation in one standard plane + } \\
\text { angulation in one standard plane + } \\
\text { axial translation + rotation } \\
\text { - Angulation in two standard planes + } \\
\text { translation in one standard plane + } \\
\text { axial translation } \\
\text { - Angulation in two standard planes + } \\
\text { axial translation + rotation }\end{array}$ \\
\hline Five-component & & $\begin{array}{l}\text { - Translation in two standard planes + } \\
\text { angulation in two planes + rotation }\end{array}$ & $\begin{array}{l}\text { - Translation in two standard planes + } \\
\text { angulation in one standard plane + } \\
\text { axial translation + rotation } \\
\text { - Translation in two standard planes + } \\
\text { angulation in two standard planes + } \\
\text { axial translation } \\
\text { - Translation in one standard plane + } \\
\text { angulation in one standard plane + } \\
\text { axial translation + rotation }\end{array}$ \\
\hline Six-component & & & $\begin{array}{l}\text { - Translation in two standard planes + } \\
\text { angulation in two standard planes + } \\
\text { axial translation + rotation }\end{array}$ \\
\hline
\end{tabular}

${ }^{*}$ Solomin LN. The Basic Principles of External Skeletal Fixation using the llizarov and Other Devices. Wurzburg. Springer-Verlag, 2012

\section{RESULTS}

The medical records of 42 patients with limb deformities (43 limbs) managed with the Ortho SUV Frame were identified. However, only 29 patients with deformities (30 limbs) qualified to be included in the study. Three were still undergoing corrections during the review and the other 10 have incomplete records/charts.

Majority of the patients were male (23/29) and with a mean age of 34.7 years (range $11-60$ ).
Twenty nine of the $30 \mathrm{limb}$ deformities involved the long bones and only one affected the joint (knee). Of the 29 long bones, 18 involved the femur, 10 involved the tibia, and 1 involved the humerus. Seventy-seven percent of the deformities (23/30) were caused by trauma. Three were Blounts disease (one case was bilateral and another unilateral), 2 were acquired from a previous infection and the other 2 deformities were due to bone tumors. Of the 23 trauma cases, 3 were acute fractures, and the other 20 were either fracture complications, or complication from a previous treatment. 
Based on the Solomin Classication, 5 were simple deformities, 17 were middle deformities and 8 were complex deformities.

An average of 34.4 days (range: 1 - 74) was needed to correct the 5 simple deformities, 61.2 days (range: 1 - 201) for the 17 middle deformities and 51.8 days (range: 1 - 90) for the 8 complex deformities.

In $87 \%$ of cases (26 of 30 ), the deformities were corrected based on the turning schedule as provided by the Ortho SUV application without any further surgical intervention. However, in 13 of these cases, the turning schedule was recomputed to achieve the final desired correction. Recomputation was done either as planned or when placement of struts' position needed re-positioning in another part of the rings. There are cases wherein rechecking/ recomputation of correction are foreseen during the course of the management. Example of cases (especially in inguinal and buttocks region) include those identified who would have unwanted strut placement as the deformity is corrected. Three cases did not achieve the desired correction as initially planned and this was due to soft tissue interposition between the bone fragments. Surgical freeing of the bone ends from the interposed soft tissue and then recomputation resulted to the desired correction. One case did not require recomputation but a closed manipulation to correct a residual posterior translation.

Table 2. Demographics of patients with deformities included in the study $(N=29)$

\begin{tabular}{|c|c|c|c|c|c|c|c|c|c|c|}
\hline Pt \# & Age & Sex & Part & Cause & $\begin{array}{l}\text { OR prior to } \\
\text { SUV application }\end{array}$ & $\begin{array}{l}\text { Total \# of } \\
\text { Days for } \\
\text { correction }\end{array}$ & $\begin{array}{c}\text { \# of } \\
\text { Revisions }\end{array}$ & $\begin{array}{l}\text { Deformity } \\
\text { Classification }\end{array}$ & $\begin{array}{l}\text { Deformity } \\
\text { corrected }\end{array}$ & Complications \\
\hline 1 & 60 & $\mathrm{M}$ & Tibia & Old Trauma & None & 47 & 2 & $M$ & YES & None \\
\hline 2 & 33 & $M$ & Femur & Old Trauma & ORIF w/ mult screws & 168 & 3 & $M$ & YES & None \\
\hline 3 & 11 & $M$ & Tibia & Blounts & None & 1 & 0 & $\mathrm{~S}$ & YES & None \\
\hline 4 & 57 & $\mathrm{~F}$ & Tibia & $\begin{array}{l}\text { Soft tissue } \\
\text { sarcoma }\end{array}$ & Wide excision & 46 & 1 & $M$ & YES & $\begin{array}{l}\text { Pin tract swelling } \\
\text { and erythema }\end{array}$ \\
\hline 5 & 40 & $M$ & Femur & Old Trauma & None & 20 & 1 & $M$ & YES & None \\
\hline 6 & 57 & $M$ & Tibia & Old Trauma & None & 90 & 1 & $M$ & YES & None \\
\hline 7 & 36 & $\mathrm{~F}$ & Tibia & Old Trauma & None & 20 & 0 & $\mathrm{~S}$ & YES & None \\
\hline 8 & 12 & $M$ & Tibia $\times 2$ & Blounts & None & R 76 / L 74 & $\mathrm{R}-1 / \mathrm{L}-1$ & R-S / L-S & YES & None \\
\hline 9 & 15 & $\mathrm{~F}$ & Femur & Old Trauma & Application of TSF & 61 & 0 & $M$ & YES & None \\
\hline 10 & 38 & $\mathrm{~F}$ & Femur & Old Trauma & Kuntscher nailing & 42 & 6 & $M$ & YES & None \\
\hline 11 & 31 & $M$ & Tibia & Bone Tumor & None & 201 & 1 & $M$ & YES & $\begin{array}{l}\text { Pin tract swelling } \\
\text { and erythema }\end{array}$ \\
\hline 12 & 32 & $M$ & Femur & Old Trauma & None & 90 & 0 & $M$ & YES & $\begin{array}{l}\text { Pin tract swelling } \\
\text { and erythema }\end{array}$ \\
\hline 13 & 56 & $M$ & Femur & Old Trauma & None & 77 & 0 & C & YES & None \\
\hline 14 & 27 & $M$ & Femur & Old Trauma & IM nailing femur & 30 & 0 & $\mathrm{C}$ & YES & None \\
\hline 15 & 24 & $M$ & Femur & Acute Trauma & None & 1 & 0 & $M$ & YES & None \\
\hline 16 & 26 & $\mathrm{M}$ & Femur & Old Trauma & None & 1 & 0 & $\mathrm{C}$ & YES & None \\
\hline 17 & 26 & $M$ & Femur & Old Trauma & None & 60 & 0 & $M$ & YES & $\begin{array}{l}\text { Pin tract swelling } \\
\text { and erythema }\end{array}$ \\
\hline 18 & 34 & $\mathrm{~F}$ & Tibia & Infection & I\&D at $4 \mathrm{y} / \mathrm{o}$ & 25 & 0 & $M$ & YES & $\begin{array}{l}\text { Soft tissue } \\
\text { impingement }\end{array}$ \\
\hline 19 & 23 & $F$ & Femur & Old Trauma & None & 90 & 1 & C & NO & $\begin{array}{l}\text { Residual posterior } \\
\text { translation }\end{array}$ \\
\hline 20 & 45 & $M$ & Femur & Old Trauma & None & 90 & 0 & $C$ & YES & None \\
\hline 21 & 33 & $M$ & Femur & Old Trauma & None & 45 & 3 & $M$ & $\mathrm{NO}$ & $\begin{array}{l}\text { Soft tissue } \\
\text { impingement }\end{array}$ \\
\hline 22 & 23 & $M$ & Femur & Old Trauma & None & 60 & 0 & $\mathrm{C}$ & YES & None \\
\hline 23 & 45 & $M$ & Humerus & Acute Trauma & None & 1 & 0 & $M$ & YES & None \\
\hline 24 & 43 & $M$ & Femur & Old Trauma & None & 7 & 2 & $M$ & YES & $\begin{array}{l}\text { Soft tissue } \\
\text { impingement }\end{array}$ \\
\hline 25 & 37 & $M$ & Femur & Old Trauma & None & 45 & 2 & $C$ & NO & None \\
\hline 26 & 46 & $M$ & Femur & Old Trauma & None & 21 & 1 & $C$ & YES & None \\
\hline 27 & 42 & $M$ & Tibia & Infection & $\begin{array}{l}\text { Plating of tibial } \\
\text { plateau, Ilizarov } \\
\text { for COM }\end{array}$ & 77 & 0 & $M$ & YES & None \\
\hline 28 & 19 & $M$ & Knee joint & Old Trauma & IM nailing femur & 1 & 0 & $\mathrm{~S}$ & YES & None \\
\hline 29 & 34 & $M$ & Femur & Old Trauma & None & 60 & 0 & $M$ & YES & None \\
\hline
\end{tabular}


In the end, all deformities were corrected as to the desired length, axial and rotational alignment (see Figures 1 - 10 for 3 sample cases). And all cases eventually went on to full consolidation/union and maintenance of the deformity correction.

The other complication noted was pin tract swelling and erythema in 13\% (4/30) of the cases. These resolved after administration of oral antibiotics, wound care with or without antibiotic cream, with or without surgical release of the pin tracts.
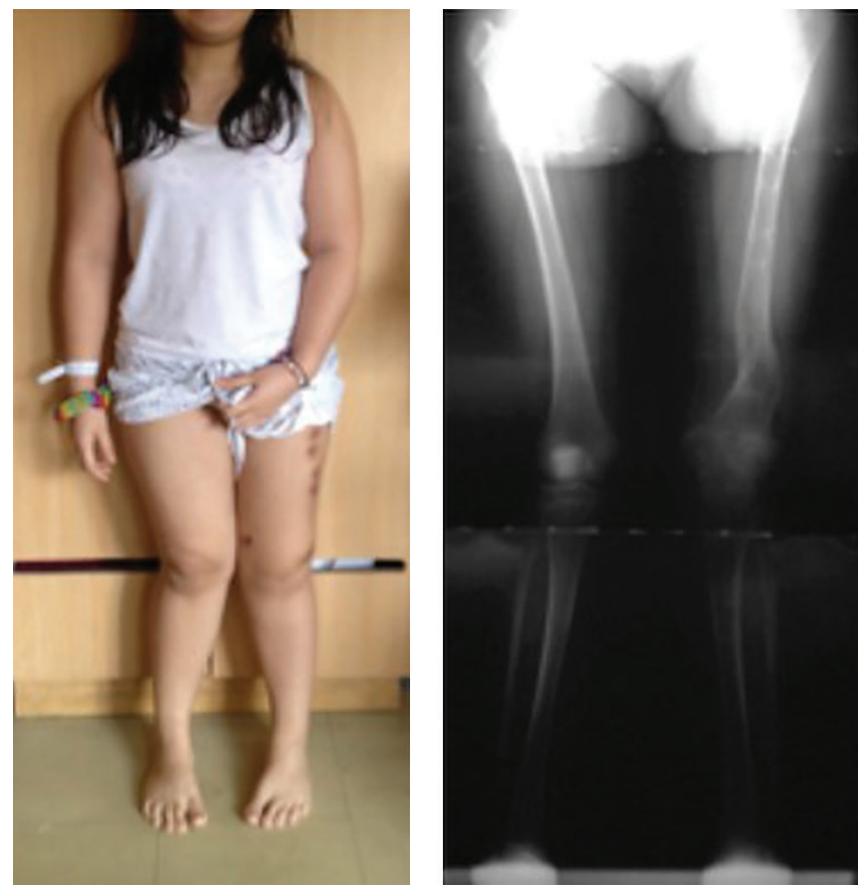

Figure 1. Case 1 - 12-year-old female with bilateral genuvalgus s/p correction of the left with Taylor Spatial Frame.
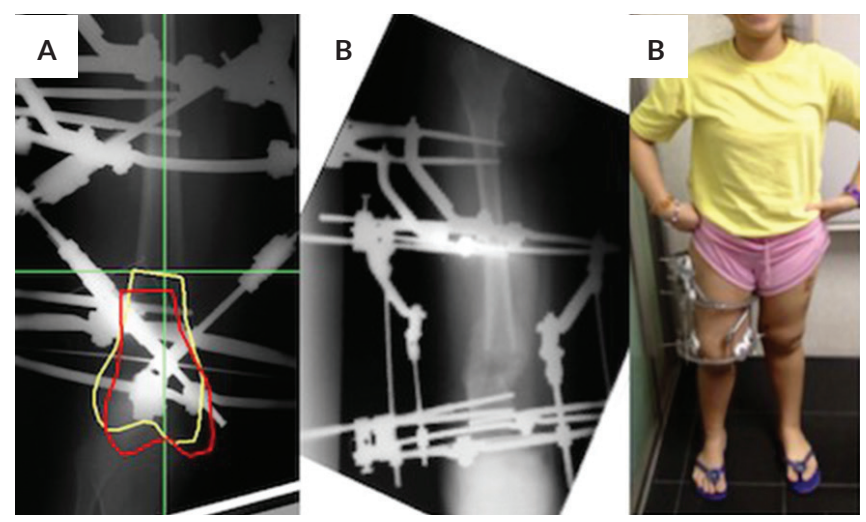

Figure 2. Case 1 - (A) Computer navigation showing pre (yellow figure) and projected post-correction (red figure) position of distal fragment. (B) X-ray image after correction and shift to regular struts. (C) Patient with OSF struts replaced with regular struts.

\section{DISCUSSION}

Accuracy of deformity correction by Ilizarov Method increases with surgical experience. ${ }^{8}$ With the advent of computer assisted systems, the accuracy of correction became less of a problem. The Ortho SUV frame (OSF) is one of several computer-assisted hexapod external fixators that are in current use. Compared to the other hexapods, it is flexible and modular in that the struts may be used on any available external fixator ring design and that the placement

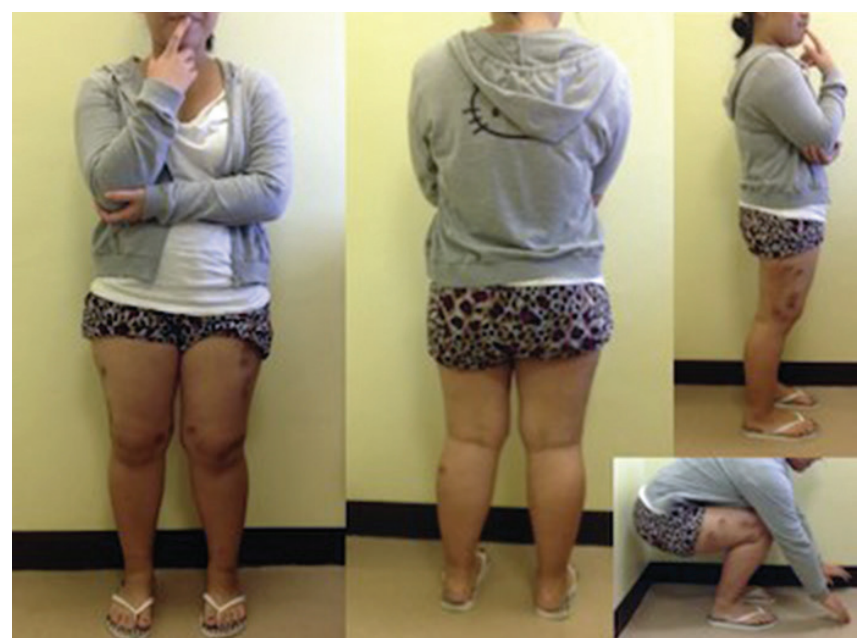

Figure 3. Case 1 - Patient post removal of Ilizarov fixator.

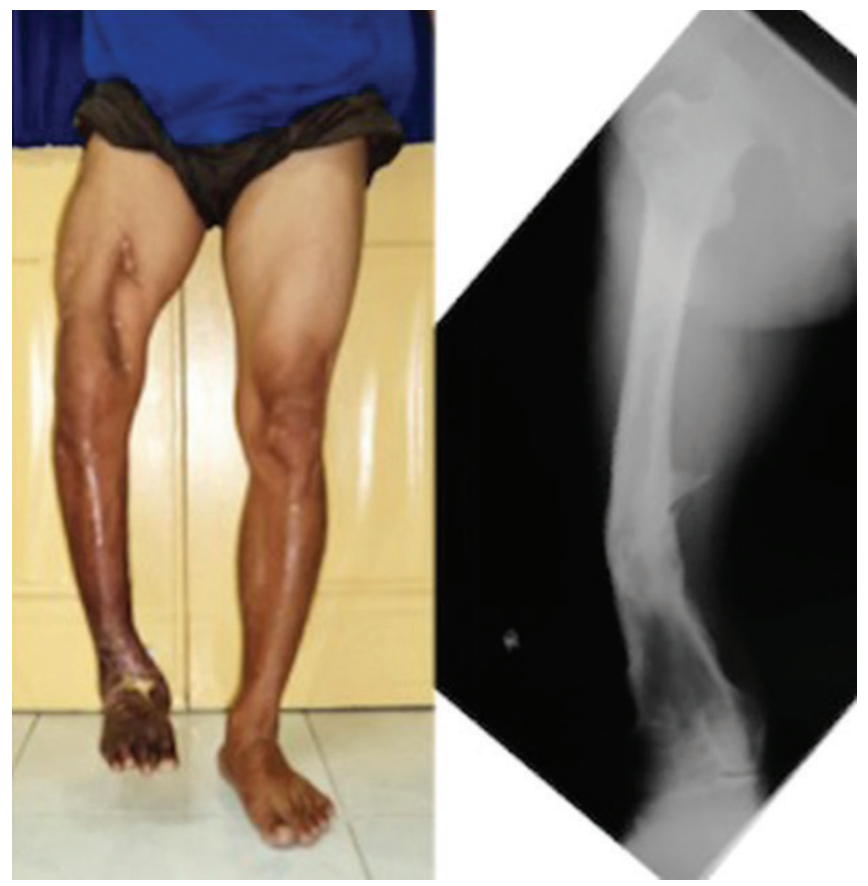

Figure 4. Case 2 - 57-year-old male with malunion of the femoral shaft secondary to premature removal of external fixator. Varus angulation of $30^{\circ}$, internal rotation $5^{\circ}$, shortening of $6 \mathrm{~cm}$. 


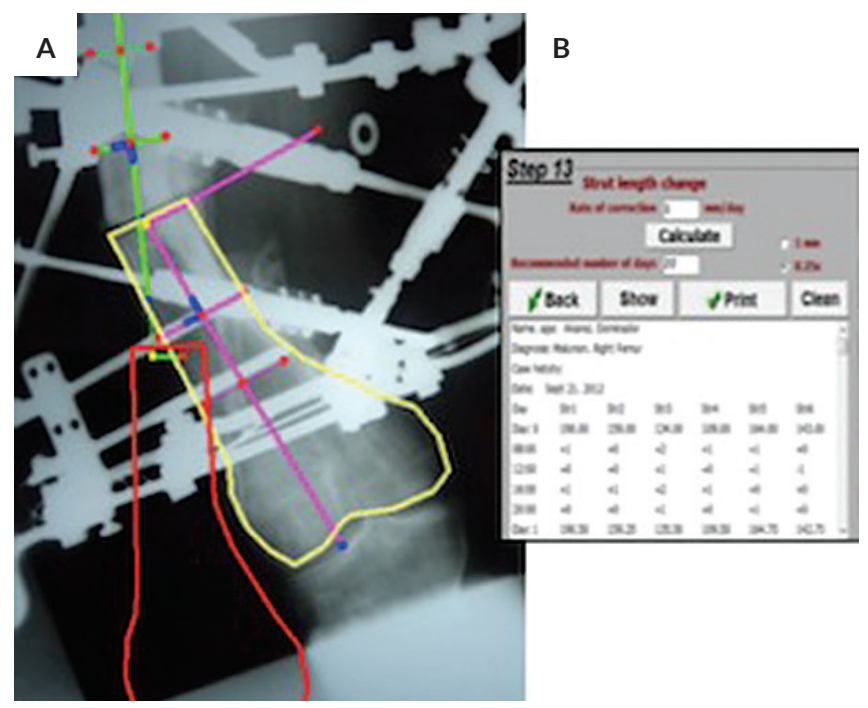

Figure 5. Case 2 - (A) Outline of pre-correction distal femur (yellow line) and projected post correction distal femur (red outline). (B) Turning schedule table.

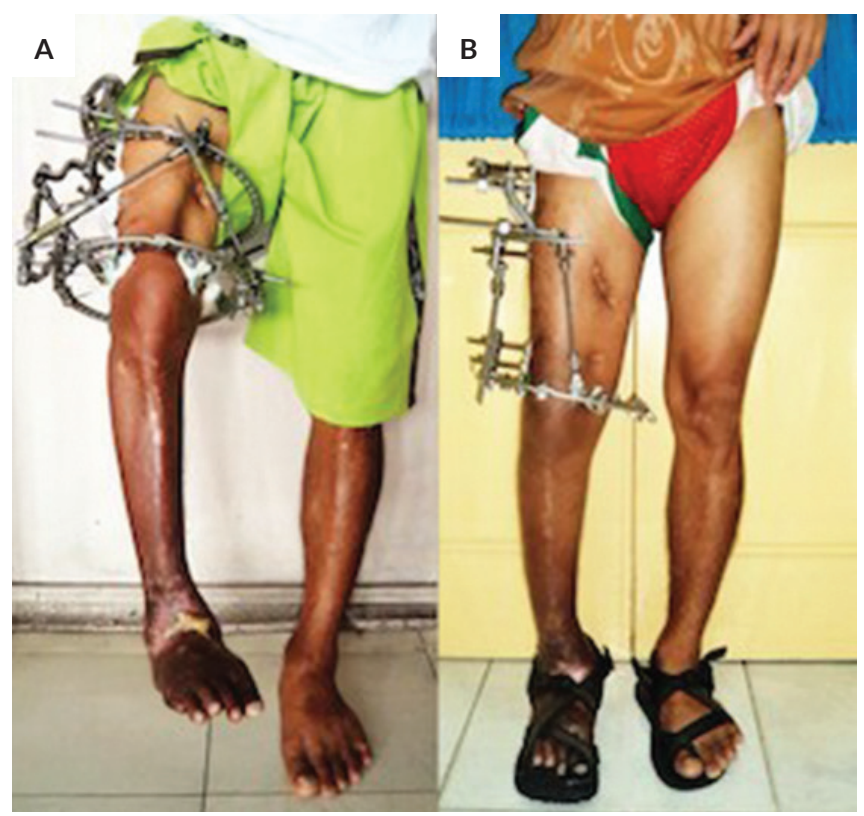

Figure 6. Case 2 - (A) Ortho SUV frame during deformity correction. (B) Modular transformation (replacement of the Ortho SUV struts to regular llizarov threaded rods) after correction.

of the struts is not pre-determined. It also uses actual x-ray images in plotting the correction with the software. These differences are due to the different mathematical platform ${ }^{6,9}$ its software is based on and the unique design of the junction of the struts. Clinical studies, mostly Russian, described and compared the use of Ortho SUV frame to other external fixators for correction of limb deformities and found it to produce good results. ${ }^{9}$
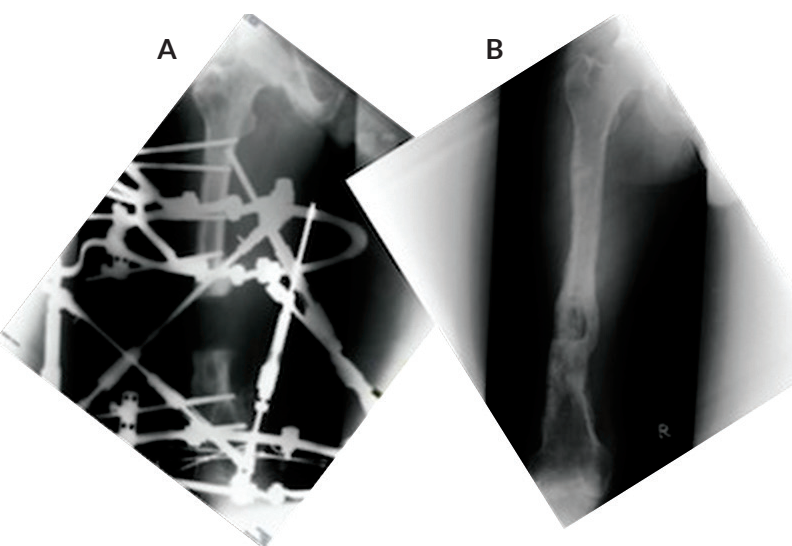

Figure 7. Case 2 - (A) Correction with Ortho SUV frame. (B) $\mathrm{X}$-ray one year post-op.
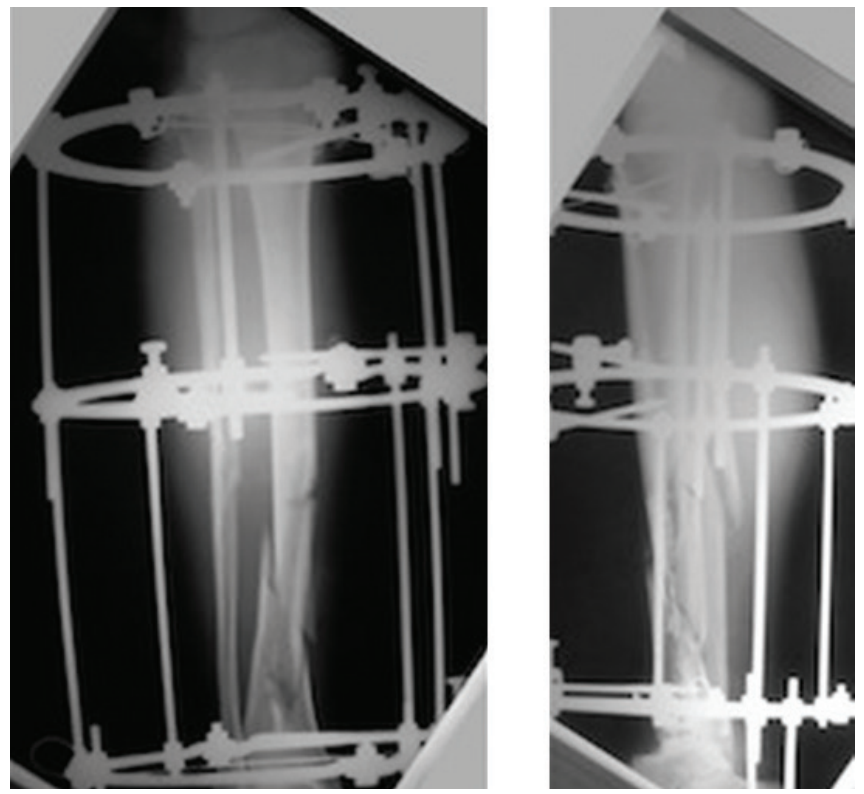

Figure 8. Case 3 - 38-year-old male with Closed Comminuted tibial Fracture initially treated with Ilizarov Fixator, with note of residual translational deformity.

Solomin, et al. compared the Ortho SUV Frame to the Ilizarov Apparatus (IA) in 127 cases of femoral deformity correction. He found that using the OSF simplifies deformity correction and reduces correction time by 2.3 times in complex deformities and by 1.6 times in middle deformities. Accuracy of correction with OSF was significantly higher than correction with IA. ${ }^{9}$

Similarly, Takata, et al, showed good results when the OSF was used to correct foot deformities. All deformities were corrected as planned. ${ }^{10}$

This review of our cases aims to describe our experience with the use of the OSF and see if we can approximate the results of the originators. From the $30 \mathrm{limb}$ deformities in 29 patients treated, we managed to correct the deformities 

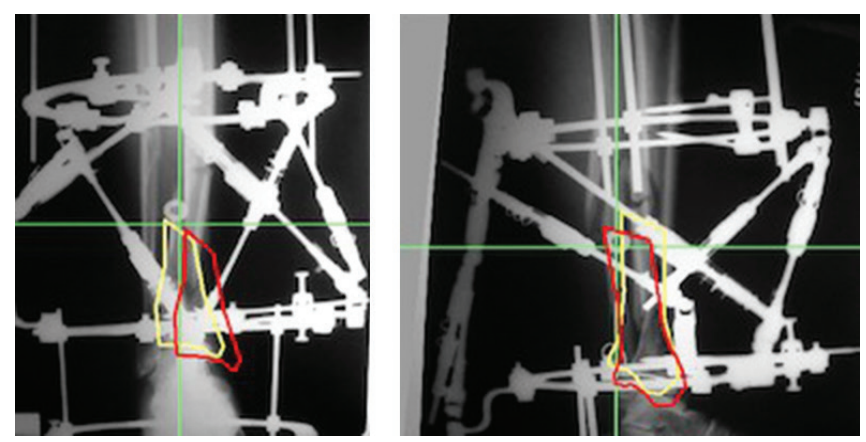

Figure 9. Case 3 - Regular llizarov threaded rods replaced with Ortho SUV struts. Red figure shows expected corrected position as determined by software.

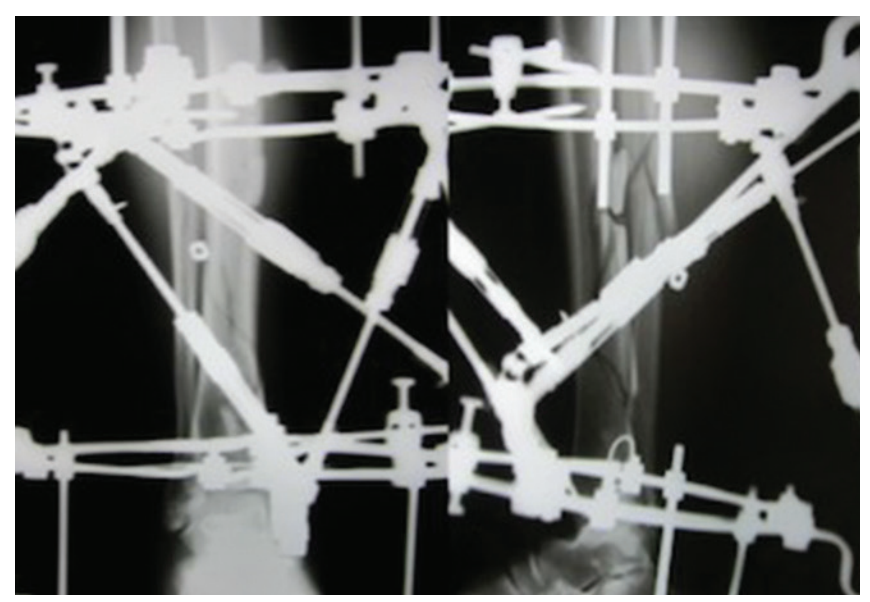

Figure 10. Case 3 - Accurate correction after acute correction and adjustment of struts as determined by software.

accurately with the OSF and its accompanying computer software in $87 \%$ (26/30) without resorting to any further surgical intervention. The correction was achieved without the time-consuming and challenging steps of reconfiguring the hinge placements as one corrects the problems one at a time beginning with length problem, followed by the angular and translation deformities and finally the rotational deformity. A certain amount of experience or proficiency is required in accomplishing these steps with accuracy. ${ }^{8}$ There is less need for this demanding skill set when the OSF is used. Correction in the long run is made easier compared to using the traditional Ilizarov Apparatus. We also found it advantageous that any kind of ring may be used and that strut placement is not predetermined and the surgeon is given leeway where the struts could be placed effectively and conveniently.

We take note that there was a need for recomputation in half the cases but without any surgical procedure being performed. In these cases, the surgeon recomputes to titrate the turning schedule as a response to either bone regeneration taking too slow or too fast. Adjustments in the choice of ring holes that the struts are located, replacement of struts as length is gained during the course of correction necessitate recomputation. All these could be done even in the middle of the correction process.

Even the remaining four cases achieved good correction with just a simple surgical procedure. The three cases underwent surgical removal of the soft tissue block and another required manipulation for a posterior translation.

The time required to achieve correction varied greatly with a range of 1 day to 201 days. This can be attributed to the heterogeneity of the cases. The time required to correct the deformity is not only dependent on the capabilities of the Ortho SUV frame itself but also on the adeptness of the surgeon in using the frame and the many clinical challenges of the cases. These factors include amount of bone transport/lengthening required, soft tissue status, response to bone regeneration and the complexity of the deformity.

We have applied the OSF to acutely correct fresh complex fractures. After a regular circular external fixator has been applied, the OSF struts then replaced the regular Ilizarov struts. The deformity was then acutely corrected (based on the computation provided by software). Experience of the authors show that in acute fracture cases, alignment correction using hinges and special conical washers is tedious and difficult once Ilizarov rings are already fixed in place. OSF can even correct for minor misalignment in all planes. After the correction, the OSF struts were replaced back with regular Ilizarov threaded rods. These cases were marked as needing 1 day for correction.

The OSF struts may or may not be retained until full consolidation. Correction achieved by the OSF can be maintained even if the OSF struts are replaced by regular threaded rods, conical washers and other regular Ilizarov components. Replacement of the OSF struts have a couple of advantages. The weight and bulkiness of the Ilizarov external fixator construct is diminished once the OSF struts are replaced. The OSF struts are expensive and limited in supply locally. The OSF struts are reusable. Consequently, more struts will be available for succeeding cases.

As expected, those with simple deformities required shorter time for the correction (ave. 34.4 days) while the middle and complex cases required around double the time (61.2 days for middle and 51.8 days for the complex). The predicted correction using the OSF were realized. Though we must stress that the accuracy of the correction would be dependent not just on the frame itself but also to the continued stability of the fixation of the ring fixators to the bone. The proper application of the fixator and maintenance of stability are a must otherwise the desired correction computed and adjusted through the turning of the struts would not be properly effected on the bone.

Compared to a regular Ilizarov rod/strut, the OSF is a more patient friendly device since it has markings which can help the patient monitor the turning schedule. Also, since the OSF simultaneously corrects multiple deformities, it greatly reduces the time that the patient needs to be in a fixator. 


\section{CONCLUSION}

In conclusion, the Ortho SUV Frame is an effective, convenient and accurate tool for correcting limb deformities. It allows simultaneous correction of multiple angular, rotational, translational and longitudinal deformities without having to do the tedious task of revising hinge placement. This capability makes the process simpler both for the patient and orthopedic surgeon.

\section{Ethical considerations}

This study was submitted, reviewed and approved by the UP Manila Research Ethics Board (UPMREB). This study is purely a medical record review, hence there's no human participation. Data collected in this study was used for research purposes only and will be kept confidential. Knowledge obtained from the study will benefit future patients in terms of management.

\section{Statement of Authorship}

All authors participated in data collection and analysis, and approved the final version submitted.

\section{Author disclosure}

All authors declared no conflicts of interest.

\section{Funding source}

This paper did not receive any funding from any institution or company.

\section{REFERENCES}

1. Sabharwal S, Rozbruch SR. What's New in Limb Lengthening and Deformity Correction. J Bone Joint Surg Am. Dec 2011; 93(4): 2323-32.

2. Sabharwal S, Green S, McCarthy J, Handy RC. What's New in Limb Lengthening and Deformity Correction. J Bone Joint Surg Am. Jan 2011; 93(2): 213-21.

3. Sabharwal S, Fragomen A, Iobst, C. What's New in Limb Lengthening and Deformity Correction. J Bone Joint Surg Am. Aug 2013; 95(16): 1527-34.

4. Maiocchi, AB, Aronson J. Ed. Operative Principles of Ilizarov. Milan: Medi Surgical Video.1991.

5. Solomin, LN, et al. Chapter 148, Ortho-SUV Frame in Textbook of Orthopedics and Trauma, 3rd edition. New Delhi. Jaypee Publishers, pp 1199-1204. 2015.

6. Solomin LN. The Basic Principles of External Skeletal Fixation using the Ilizarov and Other Devices. Wurzburg. Springer-Verlag, 2012.

7. Solomin L, Utekhin A, Vilensky V. Deformity Correction and Fracture Treatment by Software-based Ortho-SUV Frame, User Manual. St. Petersburg. Vreden Russian Research Institute of Traumatology and Orthopedics «Ortho-SUV» Ltd. 2016.

8. Tetsworth KD, Paley D. Accuracy of Correction of Complex Lower Extremity Deformities by the Ilizarov Method. Clin Orthop Relat Res. April 1994; 301:102-1

9. Solomin L, Paley D, Shchepkina E, Vilensky V, Skomoroshko P. A Comparative Study of the Correction of Femoral Deformity between the Ilizarov Apparatus and Ortho-SUV Frame. International Orthopaedics. 2014 Apr; 38 (4): 865-72.

10. Takata M, Vilensky VA, Tsuchiya, H, Solomin, LN. Foot Deformity Correction with Hexapod External Fixator, the Ortho-SUV Frame. J Foot Ankle Surg. 2013; 52 (3):324-330. 